\title{
Spatial Correlation Manifestations of Gold Mineralization of the Yenisei Ridge and the Siberian Platform with Stripes Shift Gravity Anomalies
}

\author{
Stanislav M. Makeev* \\ Siberian Federal University \\ 79 Svobodny, Krasnoyarsk, 660041, Russia
}

Received 28.02.2017, received in revised form 17.05.2017, accepted 20.03.2018

\begin{abstract}
To test the idea of Basin mechanism formation for large ore deposits, we studied a new type of anomalies of the gravitational field - stripes shift, identified with the help of the original method of analysis of the azimuthal dispersion of field. Was installed non-random nature of the spatial correlation of gold objects of the Yenisei Ridge and the Siberian platform with stripes shift of gravity anomalies, interpreted as a stretching zone. In unity with the compression zones, which map boundaries of the compression area, the zones of stretching helping understand the nature of the hydraulic head of hydrothermal mineralization and predict territory with new genetic types of gold deposits in the region.
\end{abstract}

Keywords: gravitational field, the azimuthal analysis, shear bands, compression zone, stretching zone, gold, hydrocarbons, Yenisei Ridge, Siberian Platform.

Citation: Makeev S.M. Spatial correlation manifestations of gold mineralization of the Yenisei ridge and the Siberian platform with stripes shift gravity anomalies, J. Sib. Fed. Univ. Eng. technol., 2019, 12(5), 561-572. DOI: 10.17516/1999-494X-0032.

(C) Siberian Federal University. All rights reserved

* Corresponding author E-mail address: smmakeev@mail.ru 


\title{
Пространственная корреляция
}

\section{проявлений золотоносности Енисейского кряжа \\ и Сибирской платформы}

\section{с полосами сдвига гравитационных аномалий}

\author{
С.М. Макеев \\ Сибирский федеральный университет \\ Россия, 660041, Красноярск, пр. Свободный, 79
}

\begin{abstract}
Для проверки идеи о бассейновом механизме формирования крупных рудных месторождений изучен новый тип аномалий гравитационного поля - полосы сдвига, выявленные с помощью оригинального метода анализа азимутальной дисперсии поля. Установлен неслучайньй характер пространственной корреляции золоторудных объектов Енисейского кряжа и Сибирской платформы с полосами сдвига гравитационных аномалий, которые интерпретируются как зоны межсдвигового растяжения. Рассмотренные в единстве с зонами межсдвигового сжатия, картирующими непроницаемые границь областей тектонического обжатия, зонь растяжения помогают понять природу напорного механизма гидротермального рудообразования и спрогнозировать территорию, перспективную для открытия нового для региона генетического типа месторождений золота.
\end{abstract}

Ключевые слова: гравитационное поле, азимутальный анализ, полосы сдвига, зоны сжатия, зоны растяжения, золото, углеводороды, Енисейский кряж, Сибирская платформа.

\section{Введение}

Енисейская рудная провинция многие годы является лидером по добыче золота в России. На фоне наращивания производительности золотоизвлекающих фабрик и снижения содержания золота в руде поддержание этого статуса требует постоянного восполнения ресурсной базы за счет поиска новых источников золота. Актуальной геологической задачей становится выход поисковых работ за границы исторически сложившихся рудных районов Енисейского кряжа. Решать такую задачу можно не только за счет экстенсивного расширения площадей поисков объектов известных промышленных типов, но и анализируя идеи, дающие шанс на открытие месторождений золота новых для региона генетических типов.

Одна из таких идей заключается в гипотезе о бассейновом механизме образования крупных рудных месторождений по аналогии с бассейновым механизмом формирования газонефтяных месторождений [1]. Физическая суть гипотезы заключается в том, что формирование нефтяных и рудных месторождений происходит на фоне возрастающей роли процесса складкообразования. Первым флюидом, мобилизующимся при деформации горных пород, вероятно, является разогревающаяся вода из глубоких горизонтов фундамента, затронутых этим процессом. Высокая теплоемкость и химическая агрессивность ювенильной воды ведет, с одной стороны, к повышению ее минерализации (вплоть до рассолов), с другой - к постепенному разогреву горных пород, обогащенных углеродистым веществом. Создаются благоприятные условия не только для нафтогенеза, но и для подготовительной стадии рудогенеза: цикличного (вслед за цикличностью релаксации сейсмотектонических напряжений) 
выщелачивания, переноса и сорбции на углеродистом веществе широкого спектра рудных элементов, включая золото.

Эволюционный характер развития территории, вступающей в период складкообразования, предполагает опережающее по отношению к рудогенезу развитие процессов нафтогенеза, завершающегося массовой миграцией углеводородов (УВ) по флюидопроводящим зонам к депонирующим ловушкам различного типа. При этом основными факторами подготовки рудогенеза в складчатых областях являются фактор сероуглеродного метасоматоза и структурный фактор. Первый связан с наследованием от нафтогенеза значительных количеств углерода и серы, активно участвующих в рудном процессе в виде обуглероживания и пиритизации рудовмещающих пород, второй - с формированием унаследованных от нафтогенеза флюидопроводящих зон. Дальнейшее усиление складчатости приводит, во-первых, к разрушению сложившихся к этому времени ловушек с накопленными в них углеводородами и, во-вторых, к латеральному «перемещению» областей складчатости (и нафтогенеза) на смежные территории. Со временем типичные для месторождений УВ ассоциации химических элементов в областях усиления складчатости стираются, замещаясь более устойчивыми в новых термодинамических условиях рудными элементными ассоциациями.

Кроме этого, вероятен и другой, более «катастрофический» сценарий: области, максимально приближенные к источнику деформирующих породы сил, могут по геологическим меркам времени очень быстро попасть в условия интенсивной складчатости и пройти стадию нафтогенеза в ускоренном режиме, без формирования долгоживущих скоплений углеводородов, непрерывно развиваясь в направлении рудогенеза.

Оба сценария с высокой степенью вероятности предполагают, что сквозным фактором эволюции складчатых областей всегда остается структурный фактор, обеспечивающий фиксацию в пространстве и унаследование во времени долгоживущих флюидопроводящцих зон, важных для переноса как углеводородных флюидов на начальных стадиях складкообразования, так и рудных флюидов на конечных.

Реалистичность предложенной гипотезы не просто проверить, так как исторически рудная и нефтяная геология развиваются во многом независимо друг от друга. Очевидно, что сложившаяся с годами специиализащия методов поиска нефти и руды возникла из-за стремления к экономической эффективности поисковых работ. Но поскольку такая эффективность не имеет отношения к самой природе объектов поиска, разделение двух геологий не носит субстанционального характера.

В природе имеются случаи пространственной сближенности месторождений золота и нефти. В качестве важного примера следует указать на прямое пространственное пересечение золоторудных и нефтеносных полей в пределах западной части Северо-Американской платформы (рис. $1 A$ ). При этом для месторождений золота Карлинского рудного поля фиксируется прямая корреляция золотоносности пород с содержанием в них органического вещества [1]. Для западной окраины Сибирской платформы также нельзя не отметить сближенность двух месторождений-гигантов: Олимпиадинского золоторудного и Юрубчено-Тохомского нефтегазового. Учитывая, что на ранних (1957 г.) структурно-геологических картах оба объекта входили в состав единой тектонической структуры - Енисейской антеклизы [2], - можно предполо-

$$
-563-
$$



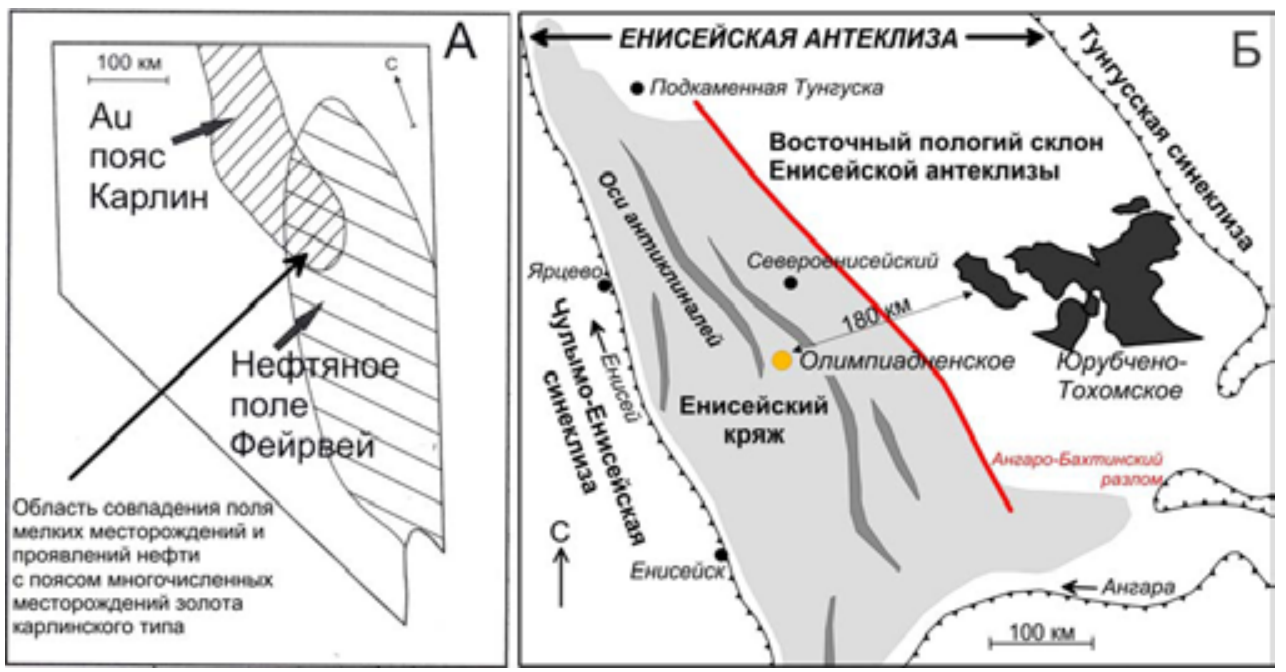

Рис. 1. Демонстрация пространственной сближенности месторождений золота и нефти на: $\mathrm{a}-$ на СевероАмериканской платформе, штат Невада [1]; б - на границе Енисейского кряжа и Сибирской платформы

Fig. 1. Demonstration of the spatial convergence of gold and oil deposits on: a - the North American Platform, Nevada [1]; 6 - the border of the Yenisei Ridge and the Siberian Platform

жить, что современная граница между ними, проведенная по Ангаро-Бахтинскому глубинному разлому, является внутренней (рис. $1 Б$ ).

Чтобы обосновать это предположение, необходимо решить две задачи. Во-первых, закартировать вышеуказанные флюидопроводящие зоны, показав, что они имеют трансрегиональный характер, во-вторых, установить характер пространственной корреляции этих зон с проявлениями золотоносности Енисейского кряжа и Сибирской платформы. Таковы задачи настоящей статьи.

\section{Методы исследования}

Для решения поставленных задач предлагается использовать оригинальный гравиструктурный метод. Выбор гравитационного поля в качестве объекта исследования обусловлен двумя причинами. Во-первых, карта гравитационного поля не учитывает (пусть и условного) разделения «двух геологий», во-вторых, необратимое перераспределение плотности при складкообразовании открывает путь к объективному исследованию сложно деформированного состояния горных пород.

В основе гравиструктурного метода лежит более общий метод частотно-азимутального анализа поля, изложенный в работах $[3,4]$. Как известно, азимут простирания выступает главным атрибутом пространственно-ориентированных геологических объектов и геометрически трактуется как луч. Вследствие этого в частотно-азимутальном методе не используются двумерные элементы анализа (пиксели, эллипсы или угловые секторы), равно как и операции интегрирования внутри них. Интегрирование внутри двумерных элементов с априорно неизвестными весовыми функциями вдоль разных азимутов неизбежно приводит к смешению информации в центральной точке таких элементов, а значит, к искажению азимутальной дисперсии изучаемого поля (особенно его низкочастотных составляющих). Поэтому в методе применяются только 
дифференциальные процедуры математической обработки данных вдоль линейных пространственных элементов, являющихся одномерными аналогами двумерных элементов, используемых в других методах частотного разложения поля в пространственной области. Таким образом, принципиально новым в методе частотно-азимутального анализа считается придание максимального значения анализу азимутальной дисперсии поля - вида дисперсии, наиболее точно описывающей деформационные состояния геологического пространства, связанные с вектором тектонического стресса.

Перенос акцента исследований с хорошо изученных видов дисперсии (амплитудной и частотной) на малоисследованный, а по сути новый, вид азимутальной дисперсии привел к возникновению и новой модели гравитационного поля, в основе которой лежит наблюдаемая дуплексная структура. Проявляется такая структура в том, что низкочастотные (отражающие глубинные источники поля) гравитационные аномалии встречаются парами синформных, относительно сближенных и сопоставимых по интенсивности аномалий противоположного знака. Вместе с характерными точками замыкания разнополярные гравитационные аномалии образуют на карте относительно изолированные объекты, названные гравитационными дуплексами (рис. 2). Дуплексы осложнены правыми и левыми сдвигами. Закономерное строение гравитационных дуплексов позволило высказать гипотезу об их деформационной природе. Суть гипотезы заключается в том, что при механическом изгибе любого блока горных пород происходит закономерное перераспределение его объема и, как следствие, плотности, которое и отражается в биполярной структуре гравитационных аномалий. Поскольку вектор силы тектонического стресса в неоднородном геологическом пространстве может быть разложен на составляющие неограниченным числом способов, то в направлении разных пространственных азимутов конфигурация дуплексов должна быть различной и, возможно, независимой друг от друга (если полагать, что геологическое пространство есть система открытая). Такое допущение позволяет изучать азимутальную структуру гравитационных дуплексов как источник нетривиальной информации о тектонических деформациях, «записанных» в виде плотностных неоднородностей горных пород.

На основе этой гипотезы предложена деформационно-сдвиговая модель поля (рис. 2), согласно которой правые и левые сдвиги отражают нарушение однородных деформаций изгиба горных пород, а области между сдвигами одного кинематического знака могут интерпретироваться как области межсдвигового сжатия или растяжения, дилатансионного ${ }^{1}$ по своей природе. Из структурной геологии известно, что пространственная близость сдвигов одного направления создает условия для локализации в межсдвиговом пространстве структур динамического сжатия (push up structure) или растяжения (pull apart structure). Поэтому раздельное картирование левых и правых сдвигов гравитационных дуплексов позволяет не только выявлять области их пространственного разделения (рис. 2), решая тем самым кинематические задачи, но и выделять в структуре поля более или менее протяженные полосы сдвига гравитационных аномалий (рис. 3). Интерпретация последних как зон межсдвигового сжатия или растяжения (далее сжатия/растяжения) открывает путь к анализу динамики межсдвиговых деформаций горных пород.

1 Дилатансия - необратимое изменение объема горных пород в процессе сдвиговых деформаций, раскрытия и закрытия трещин, переупаковки зерен при катакластическом течении горных пород. 


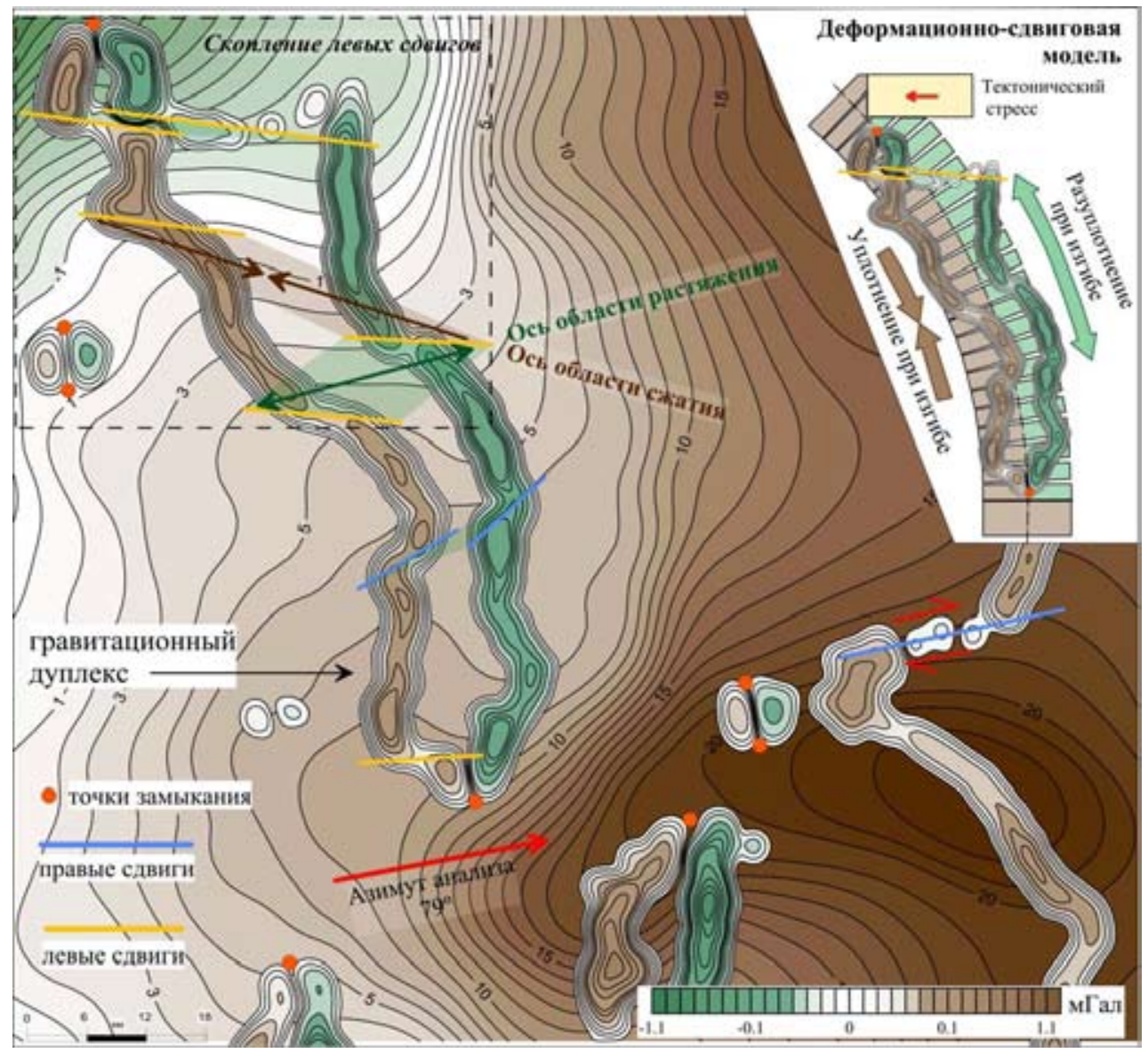

Рис. 2. Элементы дуплексной структуры гравитационных аномалий на карте азимутального состояния $79^{\circ}$ исходного поля (мГал) и деформационно-сдвиговая модель гравитационного поля

Fig. 2. Elements of the duplex structure of gravitational anomalies on the map of the azimuthal state $79^{\circ}$ of the original field $(\mathrm{mGal})$ and the deformation-shear model of the gravitational field

Следует особо отметить, и это хорошо видно на рис. 3 , что полосы сдвига не совпадают ни с амплитудными, ни с частотными характеристиками гравитационного поля и в этом смысле являются чистыми структурными феноменами. Чтобы придать им количественное измерение и возможность картирования, для каждой элементарной межсдвиговой области рассчитывается межсдвиговый потенциал $P$, который учитывает степень геометрического искажения геологического пространства в этой области и специальную весовую функцию $h$ азимутальной дисперсии поля (рис. 3).

В настоящей работе были исследованы полосы право- и левостороннего сдвига низкочастотных аномалий гравитационного поля сопредельной территории Енисейского кряжа и Сибирской платформы. Исходные данные, представленные матрицей 1х1 км аномального гравитационного поля в редукции Буге (масштаб съемки 1:200000), получены из базы данных потенциальных полей «Гравимаг» (ФГУ НПП «Геологоразведка», г. С.-Петербург). Проведенный по этим данным частотно-азимутальный анализ позволил разложить гравитационное поле в 


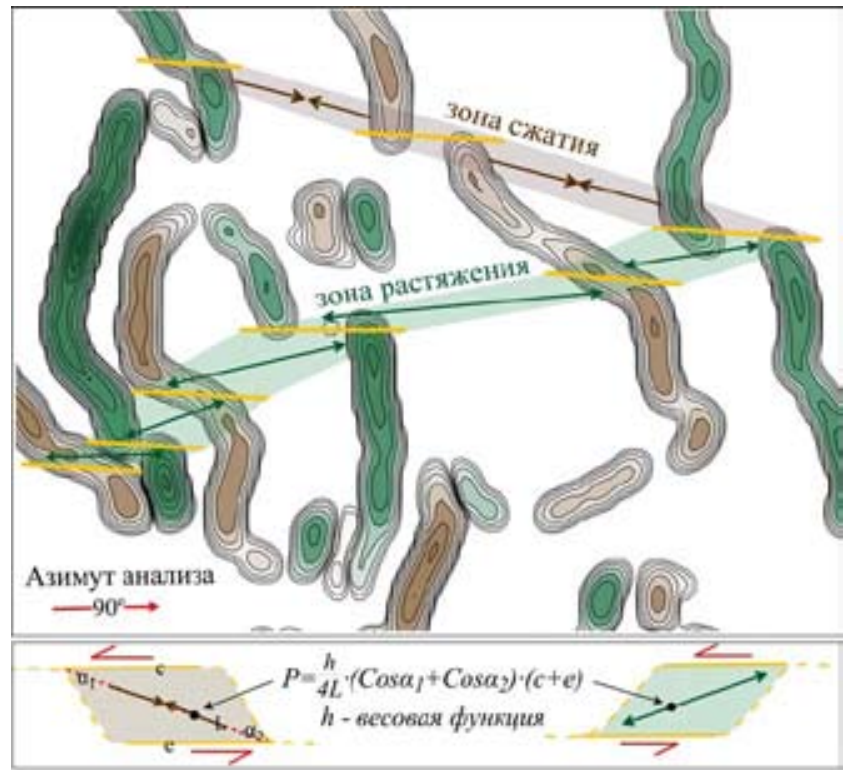

Рис. 3. Фрагмент карты азимутального состояния $90^{\circ}$ поля с полосами левостороннего сдвига осей низкочастотных гравитационных аномалий (коричневые - положительные аномалии, зеленые отрицательные), интерпретируемыми либо как зоны сжатия, либо как зоны растяжения. $P$-межсдвиговый потенциал элементарной межсдвиговой области

Fig. 3. A fragment of the map of the azimuthal state of the $90^{\circ}$ field with bands of left-handed shift of the axes of low-frequency gravitational anomalies (brown - positive anomalies, green - negative), interpreted either as compression zones or as stretching zones. $P$ - inter-shear potential of the elementary inter-shear area

контуре изученной площади ( 200000 км²) на 20 азимутальных состояний низкочастотной составляющей поля, для которой длина линейного пространственного элемента анализа равна 20 км. Каждое азимутальное состояние поля имеет вид, аналогичный рис. 2, и позволяет выделить полосы право- и левостороннего сдвига разного динамического типа (сжатия/растяжения). Рассчитав величину межсдвигового потенциала вдоль таких полос, можно закартировать зоны право- и левостороннего межсдвигового сжатия/растяжения. Суперпозиция выделенных таким образом зон право- и левостороннего растяжения показана на рис. 4.

Для изучения пространственной корреляции золоторудных объектов и зон межсдвигового растяжения применен оригинальный метод прямого статистического анализа удаленности точечных объектов от осевых линий зон растяжения. Суть метода заключается в расчете эмпирической функции удаленности $D_{\min }$ (рис. 4 ) точечного объекта от ближайшей к нему осевой линии зоны растяжения и сопоставлении этой функции с ее случайным аналогом - функцией случайного распределения $D_{0}$ (рис. 5). Общая форма графика функции $D_{0}$ определяется пространственной плотностью зон растяжения в пределах площади анализа точечных объектов (рис. 4). Положительная разница $D_{\min }-D_{0}$ является мерой неслучайности удаленности $D_{\min }$ точечных объектов от осевых линий зон растяжения. Поскольку пространственная структура аномального гравитационного поля (и выделенных на его основе зон растяжения) считается устойчивой во времени, то можно полагать, что функции $D_{0}$ и $D_{\text {min }}$ являются единственными, а отклонения $D_{\min }-D_{0}-$ неслучайными. 


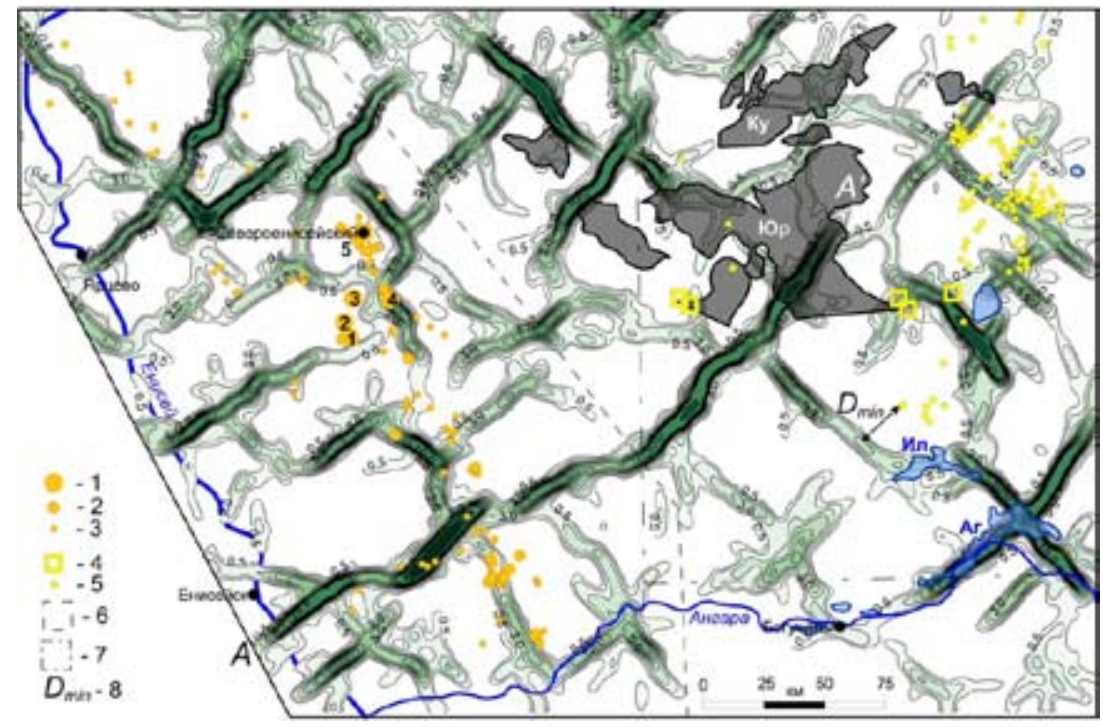

Рис. 4. Зоны межсдвигового растяжения заангарской части Енисейского кряжа и Сибирской платформы. Проявления золота: 1 - крупные (1 - Олимпиадинское, 2 - Титимухта, 3 - Благодатное, 4 - Эльдорадо, 5 - Советское) и 2 - мелкие месторождения; 3 - рудопроявления; 4 - россыпи; 5 - шлихи с золотом. Площади изучения функции удаленности: 6 - Енисейского кряжа, 7 - Сибирской платформы. Контуры месторождений: газа (Ил - Ильбокичское, Аг - Агалеевское); нефти и газа (Ку - Куюмбинское, Юр Юрубчено-Тохомское). $D_{\min }-$ в тексте

Fig. 4. Zones of inter-shear stretching of the Zaangar part of the Yenisei Ridge and the Siberian Platform. Manifestations of gold: 1 - large (1 - Olympiada, 2 - Titimukhta, 3 - Blagodatnoye, 4 - Eldorado, 5 - Sovietskoye) and 2 -small deposits; 3 - ore occurrences; 4 -gold placers; 5 - concentrates with gold. Areas of study of the distance function: 6 - Yenisei Ridge, 7 - Siberian Platform. The contours of the deposits: gas (Ил - Ilbokichskoye, Аг Agaleevskoye); oil and gas (Ky - Kuyumbinskoye, Юp - Yurubcheno-Tokhomskoye). $D_{\min }-$ in the text

\section{Результаты исследования}

Выделим три основных результата проведенного исследования.

1. Наиболее крупные месторождения газа Нижнеангарской нефтегазоносной области Агалеевское и Ильбокичское - пространственно точно совпадают с зонами межсдвигового растяжения (рис. 4), причем сложные контуры месторождений подчеркивают разную ориентированность этих зон.

2. Разноранговые объекты золотоносности Енисейского кряжа (рудопроявления, мелкие и крупные (>50 т) коренные месторождения) и Сибирской платформы (шлихи со знаками золота и мелкие россыпи) показали положительную пространственную корреляцию с зонами межсдвигового растяжения (рис. 4), подтвержденную статистически (рис. 5). При этом наметилась тенденция увеличения процента неслучайности такой корреляции по мере укрупнения ранга объекта (рис. 5).

3. Наиболее протяженная зона межсдвигового растяжения $A A^{\prime}$ ( 420 км) является трансрегиональной, соединяя золоторудные объекты на юго-западе Енисейского кряжа с восточной границей Юрубчено-Тохомского нефтегазового месторождения. Примечательно, что на северо-восточном продолжении этой зоны находится обширная область аномального шлихонакопления золота (рис. 4). 


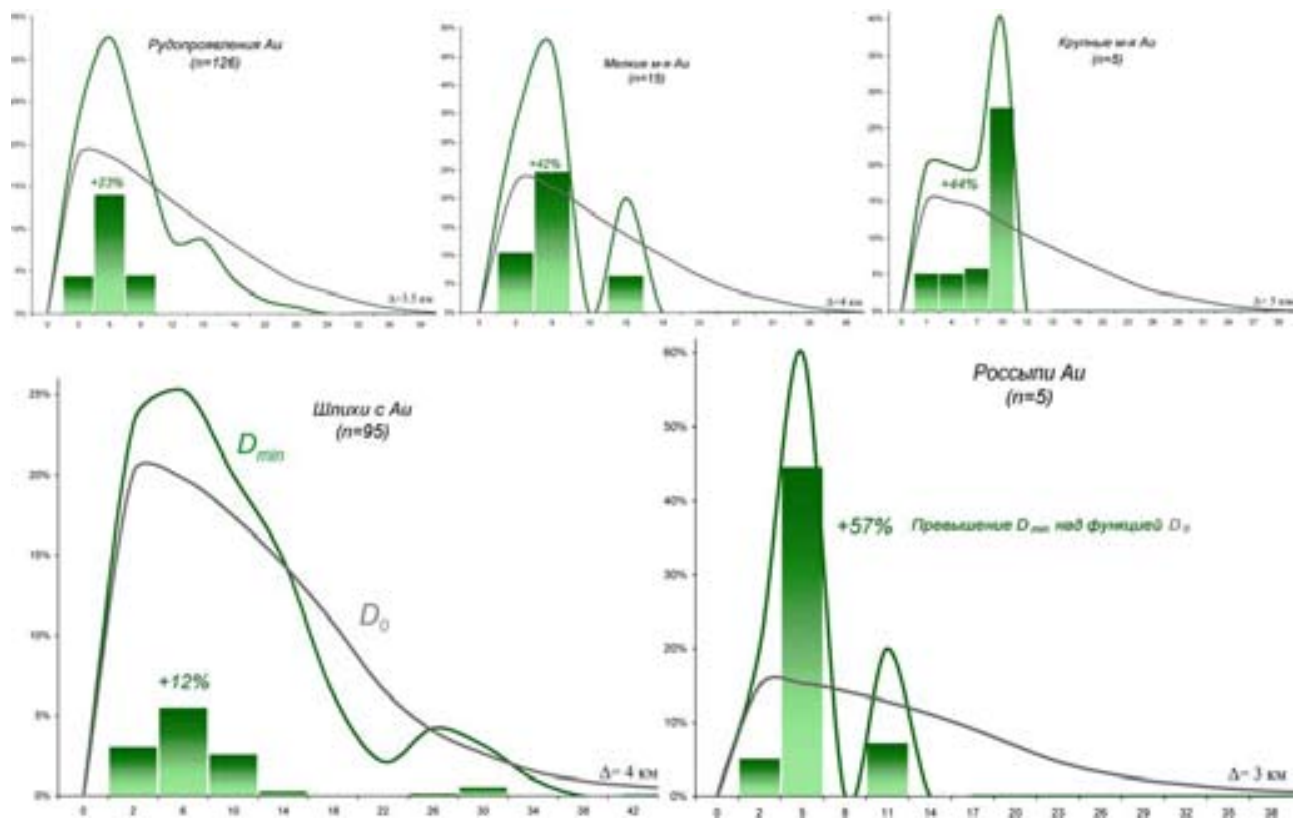

Рис. 5. Эмпирическая $\left(D_{\min }\right)$ и случайная $\left(D_{0}\right)$ функции удаленности проявлений золотоносности Енисейского кряжа и Сибирской платформы от зон межсдвигового растяжения

Fig. 5. Empirical $\left(D_{\text {min }}\right)$ and random $\left(D_{0}\right)$ distance functions of manifestations of gold of the Yenisei Ridge and the Siberian Platform from zones of inter-shear stretching

\section{Обсуждение результатов и выводы}

Проведенное исследование вполне однозначно указывает на пространственную связь месторождений газа и проявлений золотоносности Енисейского кряжа и Сибирской платформы с одним и тем же типом структурных аномалий гравитационного поля - зонами межсдвигового растяжения. Но поскольку последние, как сказано выше, являются чисто структурными феноменами, то установленная связь может показаться случайной без дополнительных соображений о возможном генезисе таких зон.

Современный взгляд на формирование нефтегазовых месторождений отводит важнейшую роль такому повсеместно наблюдаемому явлению, как аномально высокое пластовое давление (АВПД). При многообразии гипотез, объясняющих это явление, исследователи едины в одном. Для формирования АВПД и сколько-нибудь длительного его сохранения во времени необходима замкнутость, изолированность части объема горных пород, т.е. существование непроницаемых или весьма слабопроницаемых границ бассейна (или его части) нефтегазонакопления. Одной из наиболее вероятных причин возникновения АВПД считается уменьшение вдоль таких границ объема горных пород за счет их тектонического сдавливания [5].

Опираясь на эту идею, вышеописанным методом была построена карта зон межсдвигового сжатия горных пород (рис. 6). Полученная карта выявила ячеистую пространственную структуру, в которой зоны сжатия можно считать естественными границами разноразмерных практически замкнутых областей тектонического обжатия бассейнового типа. Уникальное Юрубчено-Тохомское нефтегазовое месторождение разместилось внутри наиболее обширной 


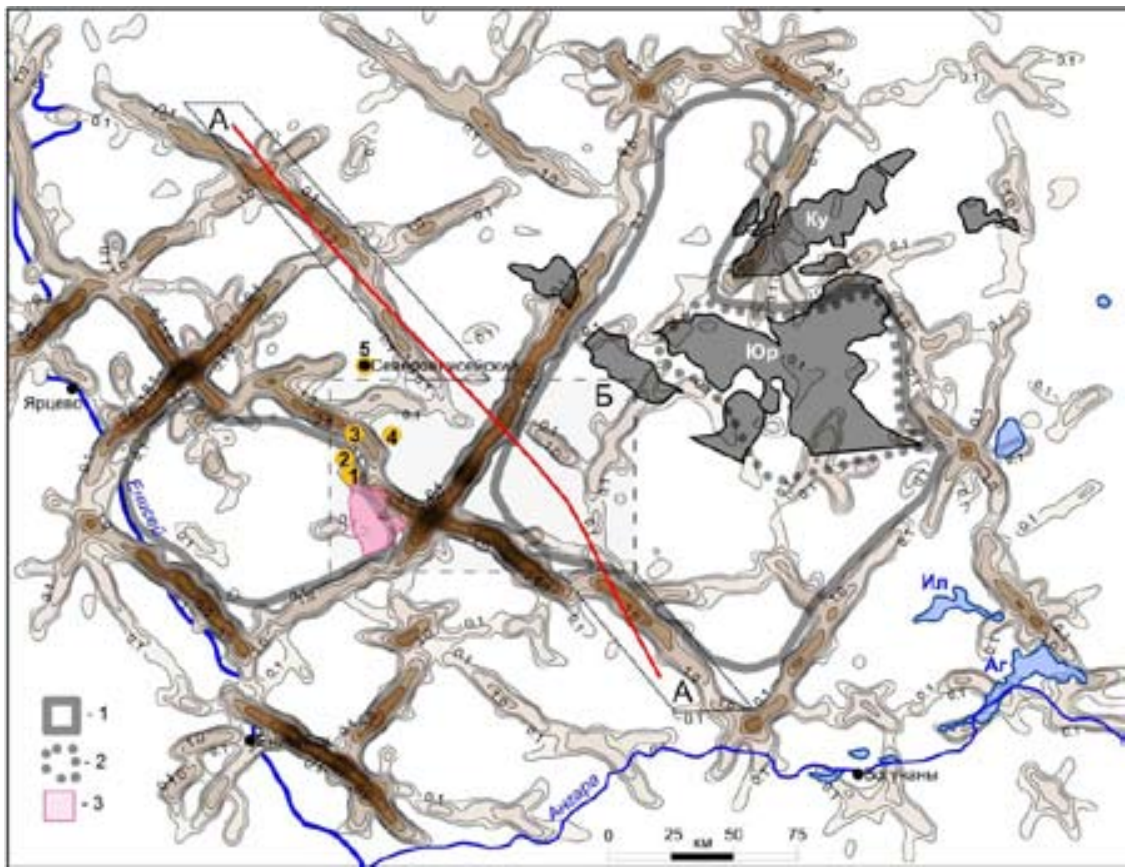

Рис. 6. Зоны межсдвигового сжатия заангарской части Енисейского кряжа и Сибирской платформы: 1 - крупнейшие области обжатия бассейнового типа; 2 - область обжатия Юрубчено-Тохомского нефтегазового месторождения; 3 - крупнейший Чиримбинский массив гранитоидов Татарскоаяхтинского коллизионного комплекса. Остальные обозначения на рис. 1, 4 и в тексте

Fig. 6. Zones of inter-shear compression of the Zaangar part of the Yenisei Ridge and the Siberian Platform: $1-$ the largest compression areas of the basin type; 2 - compression area of the Yurubcheno-Tokhomskoye oil and gas field; 3 - the largest Chirimbinsky granit massif of the Tatar-Ayahtinsky collisional complex. The remaining notation in Fig. 1, 4 and in the text

по площади области обжатия (занимая в нем более локальную вложенную область аналогичной природы), а четыре из пяти наиболее крупных месторождений золота Енисейского кряжа разместились вдоль северо-восточной границы крупнейшей области обжатия кряжа.

Если предположить, что обозначеные зоны межсдвигового сжатия горных пород и есть непроницаемые границы бассейнов тектонического обжатия, являющиеся источниками АВПД для близлежащих областей геологического пространства, то установленная пространственная связь между месторождениями УВ, золота и зонами растяжения становится более понятной. Для формирования и тех и других необходим источник АВПД, обеспечивающий постоянный или циклически действующий гидродинамический напор к зонам межсдвигового растяжения. Последние на разных этапах эволюции складчатости в пределах областей обжатия являются флюидопроводниками или газа и микронефтей, или рудного вещества.

Вопрос о том, почему не во всех ячейках ажурной структуры зон сжатия формируются месторождения и почему в одних случаях флюиды несут рудное вещество, а в других УВ не может быть решен в рамках предлагаемого чисто структурного метода. Однако в комплексе с классическими методами рудной и нефтяной геологии этот метод позволит существенно продвинуться по пути установления истинного соотношения между структурным и вещественным факторами нафто- и рудогенеза. 
Практические выводы по результатам данного исследования можно сформулировать следующим образом.

1. Трансрегиональный характер наиболее протяженной зоны межсдвигового растяжения $A A^{\prime}$ (рис. 4) позволяет предположить, что современная граница между Енисейским кряжем и Сибирской платформой, проведенная по Ангаро-Бахтинскому глубинному разлому, является условной. Особенно явной эта условность становится при рассмотрении пространственной структуры зон межсдвигового сжатия. Если северо-западный и юго-восточный фланги Ангаро-Бахтинского разлома весьма уверенно трассируются зонами межсдвигового сжатия северо-западного простирания (в контурах $A$ на рис. 6), то в области $Б$ этот трассер просто отсутствует. В этой области находится точка пересечение двух протяженных (390 и 500 км) трансрегиональных зон сжатия северо-западного и северо-восточного простирания с максимальным по интенсивности межсдвиговым потенциалом. Со стороны Енисейского кряжа к этой точке примыкает крупнейший гранитный массив татарско-аяхтинского коллизионного комплекса, а со стороны Сибирской платформы - крупнейшая область обжатия бассейнового типа с Юрубчено-Тохомским нефтегазовым месторождением внутри. Таким образом, можно предположить, что область Б является своеобразным структурным окном между Енисейским кряжем и Сибирской платформой. В пределах этого структурного окна необходимо провести дальнейшие металлогенические исследования, направленные на поиски признаков низкотемпературного золотого оруденения карлинского или куранахского типов, характерных, соответственно, для Северо-Американской и Сибирской платформ, мозаично-блоковое строение которых формировалось в результате неоднократных тектономагматических активизаций.

2. Пространственная корреляция разноранговых проявлений золотоносности Енисейского кряжа и Сибирской платформы с полосами сдвига низкочастотных гравитационных аномалий, проинтерпретированных как зоны межсдвигового растяжения, еще раз подтверждает безусловную важность и, главное, универсальность структурного фактора при прогнозировании месторождений золота как в складчатых, так и в платформенных областях. Но поскольку масштаб гравиметрических карт слишком мелок (1:200000) для задач прямого прогнозирования зон межсдвигового сжатия/растяжения на уровне рудных полей и отдельных месторождений золота, то для решения задач крупномасштабного прогнозирования целесообразно использовать другие деформационно-чувствительные поля и, прежде всего, электрическое.

\section{Список литературы}

[1] Аплонов С.В., Лебедев Б.А. Нафторудогенез: пространственные и временные соотношения гигантских месторождений. М.: Научный мир, 2010. 224 с. [Aplonov S.V., Lebedev B.A. Ore and Hydrocarbon Accumulation: spatial and temporal relations of giant deposits. Moscow: Scientific World, 2010. 224 p. (in Russian)]

[2] Болдырев М.В., Петров Ю.М. Структура Енисейского кряжа и ее кинематический анализ по данным масштабов 1:200000-1:1000000. Новосибирск: СНИИГиМС, 2011. 142 с. 
[Boldyrev M.V., Petrov Y.M. The structure of the Yenisei Ridge and its kinematic analysis according to the scale of 1:200000-1:1000000. Novosibirsk: SNIIGiMS, 2011. 142 p. (in Russian)]

[3] Макеев С.М. Пространственная корреляция гравитационного поля и золоторудных объектов Енисейского кряжа. Руды и металль, 2014, (3), 17-26 [Makeev S.M. Spatial correlation between the gravitational field and gold objects of the Yenisei Ridge. Ores and metals, 2014 (3), 17-26 (in Russian)]

[4] Макеев С.М., Ануфриев А.Е. Гравиструктурные карты как новый инструмент анализа пластово-блокового строения Сибирской платформы. Геология и минерально-сырьевые ресурсы Сибири, 2015 (1), 69-78 [Makeev S.M., Anufriev A.E. Gravity-structural maps as new tool to analysis the Siberian Platform bedded-block structure. Geology and mineral resources of Siberia, 2015 (1), 69-78 (in Russian)]

[5] Дюнин В.И., Корзун В.И. Гидрогеодинамика нефтегазоносных бассейнов. М.: Научный мир, 2005. 524 c. [Dyunin V.I., Korzun V.I. Hydro-geodynamics oil and gas basins. Moscow: Scientific World, 2005. 524 p. (in Russian)] 